\title{
Preserving Mobility in Older Adults with Physical Frailty and Sarcopenia: Opportunities, Challenges, and Recommendations for Physical Activity Interventions
}

\begin{abstract}
Maxime Billot, (iD) ${ }^{1,2}$ Riccardo Calvani, (iD) 3,4 Annele Urtamo, ${ }^{5}$ Juan Luis Sánchez-Sánchez, ${ }^{6}$ Cecilia Ciccolari-Micaldi, 'Milan Chang, (iD ${ }^{7,8}$ Regina Roller-Wirnsberger, (ID) ${ }^{9}$ Gerhard Wirnsberger, ${ }^{10}$ Alan Sinclair, " Nieves Vaquero-Pinto, ${ }^{12}$ Satu Jyväkorpi, (DD ${ }^{5}$ Hanna Öhman, ${ }^{5}$ Timo Strandberg, ${ }^{13,14}$ Jos MGA Schols, (iD ${ }^{15}$ Annemie MWJ Schols, (iD ${ }^{16}$ Nick Smeets, ${ }^{17}$ Eva Topinkova, (D) ${ }^{18}$ Helena Michalkova, (iD) ${ }^{19}$ Anna Rita Bonfigli, (iD ${ }^{20}$ Fabrizia Lattanzio, ${ }^{20}$ Leocadio Rodríguez-Mañas, ${ }^{21}$ Hélio Coelho-Júnior, ${ }^{4}$ Marianna Broccatelli, ${ }^{4}$ Maria Elena D'Elia, ${ }^{4}$ Damiano Biscotti, ${ }^{4}$ Emanuele Marzetti, (iD) ${ }^{3,4}$ Ellen Freiberger ${ }^{22}$

'Clinical Gerontology, University Hospital of Limoges, Limoges, France; ${ }^{2}$ PRISMATICS (Predictive Research in Spine/Neurostimulation Management and Thoracic Innovation in Cardiac Surgery), Poitiers University Hospital, Poitiers, France; ${ }^{3}$ Università Cattolica del Sacro Cuore,

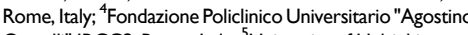
Gemelli" IRCCS, Rome, Italy; ${ }^{5}$ University of Helsinki, Department of General Practice and Primary Health Care, Helsinki University Central Hospital, Unit of Primary Health Care, Helsinki, Finland; ${ }^{6}$ Foundation for Biomedical Research Getafe University Hospital, Madrid, Spain; ${ }^{7}$ Faculty of Health Promotion, Sports and Leisure Studies, School of Education, University of Iceland, Reykjavik, School of Education, University of Iceland, Reykjavik,
Iceland; ${ }^{8}$ The Icelandic Gerontological Research Center Landspitali University Hospital and University of Iceland, Reykjavik, Iceland; 'Medical University of Graz, Department of Internal Medicine, Graz, Austria; ${ }^{10}$ Medical University of Graz, Division of Nephrology, Department of Internal Medicine, Graz, Austria; "'Foundation for Diabetes Research in Older People, Diabetes Frail Ltd., Luton, UK;

${ }_{12}$ University Hospital of Ramon Cajal IRYCIS, Madrid, Spain; ${ }^{13}$ University of Helsinki, Clinicum, Helsinki, Finland; Helsink University Hospital, Medicine and Rehabilitation, Helsinki, Finland; ${ }^{14}$ University of Oulu, Center for Life Course Health Research, Oulu, Finland; ${ }^{15}$ Department of Health Services Research, Maastricht University Medical Center, Maastricht The Netherlands; ${ }^{16}$ Department of Respiratory Medicine, School of Nutrition and Translational Research in Metabolism (NUTRIM), Maastricht University Medical Center, Maastricht, The Netherlands; ${ }^{17}$ Department of Health \& Fitness, Maastricht University Medical Center, Maastricht, The Netherlands; ${ }^{18}$ First Faculty of Medicine, Charles University, Prague, Czech Republic; ${ }^{19}$ Faculty of Social and Health Sciences, South Bohemian University, Ceske Budejovice, Czech Republic; ${ }^{20}$ Scientific Direction, IRCCS INRCA, Ancona, Italy; ${ }^{21}$ Geriatrics Service, University Hospital of Getafe, Madrid, Spain; ${ }^{22}$ Institute for Biomedicine of Aging, FAU Erlangen-Nürnberg, Nürnberg, Germany
\end{abstract}

Correspondence: Maxime Billot CHU De Poitiers, PRISMATICS (Predictive Research in Spine/Neurostimulation Management and Thoracic Innovation in Cardiac Surgery), Poitiers University Hospital, 2 Rue De La Miléterie, Poitiers 8602I, France

Tel +33549443224

Email maxime.billot2@gmail.com
This article was published in the following Dove Press journal: Clinical Interventions in Aging

\begin{abstract}
One of the most widely conserved hallmarks of aging is a decline in functional capabilities. Mobility loss is particularly burdensome due to its association with negative health outcomes, loss of independence and disability, and the heavy impact on quality of life. Recently, a new condition, physical frailty and sarcopenia, has been proposed to define a critical stage in the disabling cascade. Physical frailty and sarcopenia are characterized by weakness, slowness, and reduced muscle mass, yet with preserved ability to move independently. One of the strategies that have shown some benefits in combatting mobility loss and its consequences for older adults is physical activity. Here, we describe the opportunities and challenges for the development of physical activity interventions in people with physical frailty and sarcopenia. The aim of this article is to review age-related physio(patho)logical changes that impact mobility in old age and to provide recommendations and procedures in accordance with the available literature.
\end{abstract}

Keywords: physical exercise, muscle mass, strength, walking, balance, better aging

\section{Introduction}

One of the major challenges rising from the aging of the population is to avoid mobility impairment. Mobility is defined in a broad context by Webber et al $^{1}$ as the ability to move oneself (either independently or by using assistive devices or transportation) within environments that expand from one's home to the neighborhood and to regions beyond. Approximately one third to one half of individuals aged 65 years or older report difficulties related to walking or climbing stairs. ${ }^{1}$ Furthermore, mobility limitation during aging is associated with loss of strength and/or function that characterizes sarcopenia. ${ }^{2-4}$ Sarcopenia is described by the EWGSOP2 as a progressive and generalized skeletal muscle disorder that is associated with increased likelihood of adverse outcomes including falls, fractures, physical disability, and mortality. ${ }^{5}$ Sarcopenia is now formally acknowledged as a muscle disease with an ICD-10-MC diagnosis code. ${ }^{6}$ This medical syndrome of sarcopenia may reflect a gradual decline that impairs functional reserve in a dynamic process. On a parallel track, adverse events can drastically modify the health status of a person, which refers to the concept of frailty. An international group of experts has defined frailty as a clinical state in which there is an increase in an individual's vulnerability for developing increased dependency and/or mortality when exposed to a stressor. Frailty can occur as the result of a range of diseases and 
medical conditions. ${ }^{7,8}$ In this context, a frail individual is characterized by weak functional abilities that occur large deterioration after a minor illness. ${ }^{9}$ In order to counteract the effect of the aging process and avoid moving toward a state of frailty, functional reserve has to be strengthened, notably by physical activity. Physical activity is used as an umbrella term including exercise, leisure time physical activity, or even sports. ${ }^{10}$ Physical activity is defined as any bodily movement produced by skeletal muscles that require energy expenditure, whereas exercise is a planned, structured, repetitive movement including progression with regard to intensity. ${ }^{10}$

Frailty, especially associated with sarcopenia syndrome, is the main pivotal point to establish a preventive intervention program. Actually, there is evidence that without intervention, sarcopenia and frailty often lead to disability, falls, and a decline in quality of life. ${ }^{11}$ There is also an increased risk of hospitalization and death. ${ }^{7,8}$ That is why prevention of loss of mobility becomes a priority in this population.

Regular physical activity, exercise, and leisure time physical activity including sports, combined with an adequate diet can prevent sarcopenia and consequently frailty. A multicomponent exercise training program, which includes aerobic, strength, and balance exercises, is considered to be the most effective tool for improving mobility and gait, increasing muscle mass and strength, decreasing falls, enhancing functional performance of activities of daily living, and improving quality of life. ${ }^{12}$

This article first summarizes the functional alterations occurring in the sarcopenic and frail population. In the second part, the article highlights opportunities and challenges to prevent functional impairment, and mobility impairment through a physical activity program based on randomized clinical trials: LIFE and SPRINTT. Finally, the article provides recommendations for maintaining and improving mobility and functional performance in this specific population.

\section{Physiological Changes in the Older Population: Sarcopenia and/or Frailty \\ Muscle Strength and Power}

In old age, the most important impact on mobility arises from changes in muscle strength and power. "Strength" can be defined as the maximum force generation capacity of an individual, whereas "power" refers to the product of force and velocity of contraction. ${ }^{13-15}$ Several studies have demonstrated that strength capacities start to decline around the age of 30 years $^{16,17}$ and that the decline increases at the rate of about $12 \%$ to $15 \%$ per decade after the fifth decade, with an even faster decline after 60 years. ${ }^{18}$ Longitudinal studies have reported that strength decreases about $2.5 \%$ and $1.5 \%$ per year after sixty years old at the knee and elbow joints, respectively. ${ }^{19}$ It has consequently been suggested that alteration of muscular strength could be muscle-specific. ${ }^{20,21}$ Skelton et al demonstrated that power declines with aging at an even more rapid rate than strength. ${ }^{15}$ The origins of strength and power decline with aging are multifactorial. In two reviews, Clark and Manini ${ }^{22}$ and Vandervoort ${ }^{23}$ characterized the loss of neuromuscular strength with aging. In these reviews, the authors reported that neuromuscular strength could be directly influenced by changes in both the nervous system and the muscular system. Regarding the nervous system, the authors indicated that alteration of command drive, ${ }^{24-31}$ spinal reflex excitability, ${ }^{32,33}$ and motor unit discharge rate ${ }^{34}$ can alter strength production in older people. In the muscular system, alterations were observed in muscle mass size, ${ }^{3,35}$ muscular architecture, ${ }^{36}$ and excitation-contraction coupling, ${ }^{37}$ which can be influenced by reduction of androgen secretion and growth factor. $^{38,39}$ Studies over the last four decades have demonstrated that physiological deficiencies are clearly associated with functional performance. ${ }^{15,40-43}$

Related to physical function, there is evidence that knee extensor strength is an excellent predictor of dependency and survival, and that leg power is a stronger predictor of mobility loss than strength. ${ }^{40,44-46}$ Bean et $\mathrm{al}^{40}$ found that leg power was strongly predictive of physical performance in 45 participants aged about 73 years ( $75 \%$ women), highlighting a significant relationship with stair climb time, chair stand, tandem gait time, habitual gait velocity, maximal gait velocity and Short Physical Performance Battery (SPPB) tests (Table 1). Other studies have reported that handgrip strength is strongly associated with lower limb muscle power and physical function of daily living. ${ }^{47,48}$ In conclusion, it can be stated that muscle strength and power decline at different rates, with power decreasing more rapidly than strength. While many factors contribute to strength and power decline, muscle mass is of key importance.

\section{Muscle Mass}

As previously mentioned, the combination of low muscle strength, low physical performance, and reduction of 
Table I Overview of Tests Available for the Assessment of Balance, Gait, and Lower Extremity Function

\begin{tabular}{|c|c|c|c|}
\hline $\begin{array}{l}\text { Tested } \\
\text { Function }\end{array}$ & Name & Description & Interpretation \\
\hline $\begin{array}{l}\text { Balance } \\
\text { Gait } \\
\text { Lower } \\
\text { extremity } \\
\text { function }\end{array}$ & $\begin{array}{l}\text { Short Physical } \\
\text { Performance } \\
\text { Battery (SPPB) }\end{array}$ & $\begin{array}{l}\text { The SPPB involves three subtasks: balance test, habitual gait } \\
\text { speed, and the } 5 \text {-repetition chair stand test. Possible scores } \\
\text { range from } 0 \text { to } 12 \text {. } \\
\text { Balance test: } \\
\text { Ability to stand for } 10 \text { seconds with feet in three different } \\
\text { positions: } \\
\text { - Side-by-side (scored from } 0-1 \text { ) } \\
\text { - Semi-tandem (scored from } 0-1 \text { ) } \\
\text { - Full-tandem (scored from } 0-2 \text { ) } \\
\text { Gait speed test: } \\
\text { Timed } 4 \text {-min walk at usual pace: } \\
\text { - 0, unable to do the walk } \\
\text { - I, if time is }>8.7 \text { seconds } \\
\text { - 2, if time is } 6.21 \text { to } 8.70 \text { seconds } \\
-3 \text {, if time is } 4.82 \text { to } 6.20 \text { seconds } \\
-4 \text {, if time is }<4.82 \text { seconds } \\
\text { Chair stand test: } \\
\text { Time to rise from a chair five times as quickly as possible: } \\
-0 \text {, unable to complete five chair stands or completes stands } \\
\text { in }>60 \text { seconds } \\
- \text { I, chair stand time is } \geq 16.70 \text { seconds } \\
-2 \text {, chair stand time is } 13.70 \text { to } 16.69 \text { seconds } \\
-3 \text {, chair stand time is } 11.20 \text { to } 13.69 \text { seconds } \\
-4 \text {, chair stand time is } \leq 11.19 \text { seconds }\end{array}$ & $\begin{array}{l}\text { Total balance test score: } \_/ 4 \text { points } \\
\text { Gait speed test score: } \_/ 4 \text { points } \\
\text { Chair stand test score: } \_/ 4 \text { points } \\
\text { Total score __/ } 12 \text { points } \\
\text { (sum of points above) } \\
\text { Score and classification of limitation: } \\
\text { 0-3: Severe } \\
\text { 4-6: Moderate } \\
\text { 7-9: Low } \\
\text { 10-12: Very low/absent }\end{array}$ \\
\hline $\begin{array}{l}\text { Balance } \\
\text { Gait }\end{array}$ & $\begin{array}{l}\text { Tinetti balance } \\
\text { assessment } \\
\text { tool }^{180}\end{array}$ & $\begin{array}{l}\text { The Tinetti balance assessment tool consists of balance and } \\
\text { walking tests. Possible scores range from } 0 \text { to } 28 \text {. } \\
\text { Balance maneuvers assessment (eight items) } \\
\text { - Sitting balance scored from } 0-1 \\
\text { - Rising from chair scored from } 0-4 \\
\text { - Immediate standing balance (first } 5 \text { seconds) scored from } \\
0-2 \\
\text { - Prolonged standing balance scored from } 0-2 \\
\text { - Withstanding nudge on chest scored from 0-2 } \\
\text { - Standing balance with eyes closed scored from } 0-1 \\
\text { - Turning } 360 \text { degrees scored from } 0-2 \\
\text { - Sitting down scored from } 0-1 \\
\text { Gait observations assessment (eight items) } \\
\text { - Initiation of gait scored from } 0-2 \\
\text { - Step length scored from } 0-2 \\
\text { - Step height scored from } 0-2 \\
\text { - Step continuity scored from } 0-2 \\
\text { - Step symmetry scored from } 0-1 \\
\text { - Walking stance scored from } 0-1 \\
\text { - Amount of trunk sway scored from } 0-1 \\
\text { - Path deviation scored from } 0-2\end{array}$ & 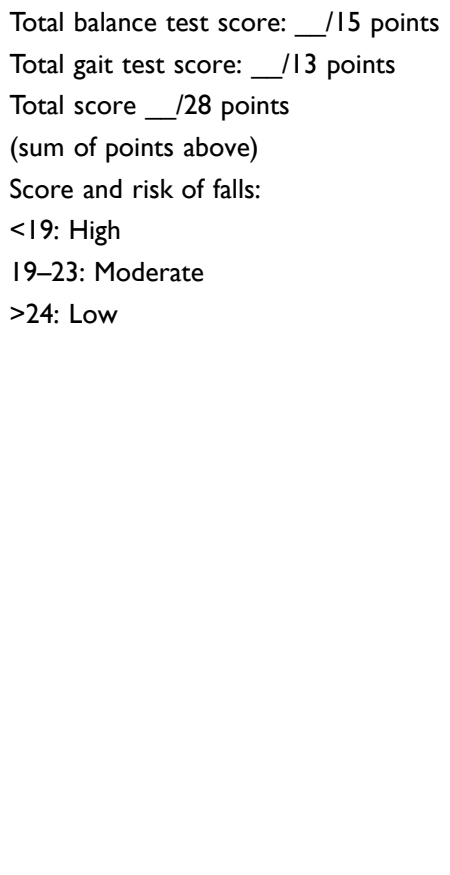 \\
\hline Balance & $\begin{array}{l}\text { One-leg balance } \\
\text { test }^{|8|}\end{array}$ & $\begin{array}{l}\text { The one-leg balance test assesses the ability to stand upright } \\
\text { on one leg. }\end{array}$ & $\begin{array}{l}\text { Score and risk of falls: } \\
<5 \text { second: High } \\
6-29 \text { seconds: Moderate } \\
>30 \text { seconds: Low }\end{array}$ \\
\hline
\end{tabular}

(Continued) 
Table I (Continued).

\begin{tabular}{|c|c|c|c|}
\hline $\begin{array}{l}\text { Tested } \\
\text { Function }\end{array}$ & Name & Description & Interpretation \\
\hline Balance & $\begin{array}{l}\text { Berg Balance } \\
\text { Scale (BBS) }\end{array}$ & $\begin{array}{l}\text { The BBS tests balance function by assessing the performance } \\
\text { of functional tasks. Possible scores range from } 0 \text { to } 56 \text {. } \\
\text { Assessments ( } 14 \text { items scored from } 0-4 \text { ) } \\
\text { - Sitting to standing } \\
\text { - Standing unsupported } \\
\text { - Sitting with back unsupported but feet supported on floor } \\
\text { or on a stool } \\
\text { - Standing to sitting } \\
\text { - Transfers } \\
\text { - Standing unsupported with eyes closed } \\
\text { - Standing unsupported with feet together } \\
\text { - Reaching forward with outstretched arm while standing } \\
\text { - Pick up an object from the floor from a standing position } \\
\text { - Turning to look behind over left and right shoulders while } \\
\text { standing } \\
\text { - Turn } 360 \text { degrees } \\
\text { - Place alternate foot on step or stool while standing } \\
\text { unsupported } \\
\text { - Standing unsupported one foot in front } \\
\text { - Standing on one leg }\end{array}$ & $\begin{array}{l}\text { Score and risk of falls: } \\
0-20 \text { : High } \\
\text { 2I-40: Moderate } \\
\text { 4I-56: Low } \\
\text { A change of at least eight points indicates an } \\
\text { actual change in function between two } \\
\text { assessments. }\end{array}$ \\
\hline $\begin{array}{l}\text { Gait } \\
\text { Lower } \\
\text { extremity } \\
\text { function }\end{array}$ & $\begin{array}{l}\text { Timed Up and Go } \\
\text { (TUG) }^{183}\end{array}$ & $\begin{array}{l}\text { TUG is used to assess mobility. } \\
\text { Participant is instructed to rise from a chair, walk three } \\
\text { meters, turn around a physical marker, walk back to the chair, } \\
\text { and sit down. }\end{array}$ & $\begin{array}{l}\text { Score and classification of mobility: } \\
<10 \text { seconds: Normal } \\
\text { 10-20 seconds: Moderate } \\
20-30 \text { seconds: Low } \\
>30 \text { seconds: Very low }\end{array}$ \\
\hline Gait & $\begin{array}{l}400-\mathrm{m} \text { walk } \\
\text { test }^{184}\end{array}$ & $\begin{array}{l}\text { The } 400-m \text { walk test assesses mobility over a long track. } \\
\text { Participant is instructed to walk at normal pace. The } 400 \text { - } \\
\text { meter path is materialized with two physical markers located } \\
20 \text { meters apart. During the test, the participant may not use } \\
\text { assistive devices (except for a cane). Criteria for interrupting } \\
\text { the test are palpitations, chest pain, constriction, feeling of } \\
\text { oppression, dyspnea, sensation of fainting, empty head, or } \\
\text { postural instability, pain in the lower limbs, vertigo, and } \\
\text { muscle fatigue. } \\
\text { The } 400 \text {-m walk time is measured using a manual } \\
\text { chronometer or an optoelectronic system with two } \\
\text { photocells connected to a digital chronometer. }\end{array}$ & $\begin{array}{l}\text { Participant unable to complete the test within } \\
15 \mathrm{~min} \text { is considered to be mobility disabled. }\end{array}$ \\
\hline Gait & $\begin{array}{l}\text { 6-Minutes } \\
\text { Walking Test }(6- \\
\text { MWT })^{185}\end{array}$ & $\begin{array}{l}\text { The 6-MWT assesses mobility and cardiorespiratory fitness. } \\
\text { Participant is instructed to walk at brisk pace he/she can } \\
\text { maintain throughout the test. The path is materialized with } \\
\text { two physical markers located at } 20 \text { meters apart. During the } \\
\text { test, the participant may not use assistive devices (except for } \\
\text { a cane). Criteria for interrupting the test are palpitations, } \\
\text { chest pain, constriction, feeling of oppression, dyspnea, } \\
\text { sensation of fainting, empty head, or postural instability, pain } \\
\text { in the lower limbs, vertigo, and muscle fatigue. } \\
\text { The 6-MWT distance is calculated by the sum lap distance ( } 40 \\
\mathrm{~m} \text { per lap) plus the distance walked during the last lap. }\end{array}$ & $\begin{array}{l}\text { Participant unable to complete at least } 332 \\
\text { meters (walking speed } 0.8 \mathrm{~m} / \mathrm{s} \text { ) is considered to } \\
\text { be mobility disabled. }\end{array}$ \\
\hline
\end{tabular}


muscle mass characterize sarcopenia. ${ }^{3-5,49}$ Sarcopenia is considered a critical point to determine the frail population and can be influenced by several factors. In a recent overview, Marzetti et $\mathrm{al}^{3}$ reported that sarcopenia can be impacted by (i) personal factors such as age, early life events, low birth weight, and genetic characteristics, (ii) hormonal factors (eg, testosterone, estrogens, growth hormone, insulin-like growth factor-1), chronic low-grade inflammation, and mitochondrial dysfunction, (iii) lifestyle habits such as decrease in food and protein intake, sedentary behavior or reduced physical activity, alcohol abuse, tobacco use, and bed rest, (iv) chronic health conditions such as cognitive impairment, diabetes, and advanced stage organ diseases.

The literature has shown that after the seventh decade, muscle mass decreases by $4.7 \%$ and $3.7 \%$ per decade in men and women, respectively. ${ }^{14}$ Using dual energy X-ray absorptiometry (DXA) to examine muscle mass in 433 individuals (180 women) aged $18-94$ years, Kyle et $\mathrm{al}^{50}$ reported that muscle mass is almost steady from 18 to 60 years, and declines after 60 years. In a magnetic resonance imagery (MRI) study in 468 individuals (200 women), Janssen et $\mathrm{al}^{51}$ also reported that the rate of loss of muscle mass of upper limbs decreases less than twice the rate of loss of lower limbs. Further, men showed larger agerelated muscle mass decrease compared to women. ${ }^{52}$

Muscle mass can be estimated with several techniques such as anthropometric measurements, bioelectrical impedance analysis (BIA), computed tomography (CT), MRI, and DXA. Each of these techniques has advantages and disadvantages in terms of cost, availability, ease of use and time consumption. ${ }^{3}$ Compared to the gold standard for quantifying muscle mass, ie CT and MRI, DXA may, due to the minimal radiation received by the patient, be the best way of differentiating fat and lean tissues. However, DXA scan is not portable, which limits its use in a large-scale population. To overcome this issue, BIA is inexpensive, easy to perform, readily reproducible, appropriate for ambulatory as well as bedridden patients, and more accurate than anthropometry. All in all, DXA could be considered as the best gold standard alternative to quantify muscle mass in research, and BIA as a valid portable alternative.

While the relationship between muscle mass decline and negative outcomes is still debated in the literature, ${ }^{14}$ recent studies provide robust evidence that sarcopenia, including loss of muscle mass, is associated with falls, physical frailty, and disability. ${ }^{3}$ Older adults with sarcopenia are reportedly less active than people without sarcopenia. ${ }^{53,54}$ Furthermore, different studies have shown that the older population with sarcopenia has a greater risk of death (whatever the causes) compared with nonsarcopenic people. ${ }^{55-59}$ From another perspective, the decrease in the circulating levels of specific hormones has been associated with both sarcopenia and osteoporosis, showing that the two processes follow a similar path. ${ }^{60}$ An observational study recently carried out among 68 prefrail older persons aged between 65 and 95 years reported that those with osteosarcopenia were at higher risk of fractures or functional decline than those with either sarcopenia or osteoporosis. ${ }^{61}$ Further, the authors showed that the performance on the handgrip strength, chair rise and sit-tostand tests were significantly lower in patients with osteosarcopenia than in those with sarcopenia or osteoporosis alone. Finally, it has been reported that the sarcopenic older population was more than threefold likely to fall than those without sarcopenia. ${ }^{62-64}$

\section{Balance and Postural Control}

It has been well documented that postural control decreases and risk of falls increases with aging. As a result, falls are a common event in older adults, with about one third of persons 65 years and older experiencing a fall event yearly. This number increases to nearly $50 \%$ in the age group 80 years and above. ${ }^{65}$ The decline in balance and postural control are multicausal. To maintain upright standing, the neuromuscular system has to generate appropriate muscular contraction involving complementary input from the visual, proprioceptive, exteroceptive and vestibular systems. ${ }^{66-71}$ Age-related alteration in these different systems results in decline of postural control. ${ }^{72-74}$ Experimental studies have shown that older persons are less able to regulate postural control when sensory information is manipulated or removed. ${ }^{72,74-76}$ In a challenging condition, such as one-leg stance, maintaining upright standing is more energy-consuming in older than in their young counterparts. ${ }^{77-79}$ Strength capacity is also useful to discriminate fallers from nonfallers, showing that the former group is weaker than the latter. ${ }^{80}$ It has also been shown that aging is associated with a progressive shift from spinal to supraspinal pathways to regulate leg muscle activity in an upright standing position. ${ }^{81}$ This finding is supported by experimental studies reporting that the frail population could require more cognitive resources to maintain upright standing, and consequently increase the delay of postural control adjustment in comparison with healthy older adults. ${ }^{82-84}$ While there is no clear evidence of specific system alteration between frail 
and nonfrail, and sarcopenia vs nonsarcopenia populations, clinical studies have shown more conclusive results.

From a meta-analysis, Yeung et $\mathrm{al}^{85}$ recently reported significant higher risk of falls in people with sarcopenia than without. Further, in a systematic review and meta-analysis of 10 studies with 10,073 participants, Zhang et al ${ }^{86}$ concluded that sarcopenia is a risk factor for falls among community-dwelling older people, but not in nursing home residents. The authors provided several explanations for this counterintuitive finding. ${ }^{87,88}$ First, nursing-home residents may have limited mobility due to their poorer health status, which may moderate the effect of sarcopenia on falls. ${ }^{89}$ In addition, in community-dwelling older adults falls were reported with questionnaires, whereas falls in nursing homes reported by nurses may be underestimated. With regard to gender, Zhang et $\mathrm{al}^{86}$ indicated that old men with sarcopenia had a higher risk of falls than older persons in mixed gender groups. These results are supported by the fact that muscle mass decreases in men are generally twice as great than in women. ${ }^{90,91}$ In addition to sarcopenia, a systematic review and meta-analysis by Kojima ${ }^{92}$ demonstrated that both frailty and prefrailty are significant predictors of future falls among community-dwelling older people. This could result from decreased functional reserve capacity in multiple physiologic systems and increased vulnerability to stressors such as accidents, disease symptoms, or adverse drug reactions. ${ }^{93}$ All in all, the literature has demonstrated an age-related increased risk of falls, especially in persons with sarcopenia and the frail population. The increased risk of falls with aging is intrinsically linked to the deterioration of the dynamic balance generated during walking and, more generally, when in relation to mobility.

\section{Walking and Mobility}

Locomotion, defined as a motor action that changes the location of the entire body within the environment, is a common daily activity in human beings. Walking speed, representing the capacity of walking, declines slightly until the sixth decade, and decreases at a faster pace thereafter. ${ }^{9,94,95}$ In a cross-sectional study, Samson et al ${ }^{95}$ evaluated the preferred walking speed over a 12-meter walkway in 118 women and 121 men aged from 19 to 90 years. The authors found an age-related decrease of gait parameters with an alternation not only in walking speed, but also in stride length. However, modification of walking patterns with age has not appeared consistently throughout the literature. Compared to young adults, some studies have reported greater stride width in older adults, ${ }^{96-98}$ while other studies have indicated lesser stride width with older age. ${ }^{99}$ Ko et al ${ }^{100}$ revealed that stride width at preferred walking speed was narrower in middle-age (32-57 years) than in old adults (58-78 years) at maximum speed, while it was wider in oldest old group (79-93 years). The authors concluded that the walking pattern alteration could be different during the aging process, and could also depend on testing conditions. The impact of the methods used to obtain walking/gait speed was also addressed by $\mathrm{Ng}$ et $\mathrm{al}^{101}$ and Wang et $\mathrm{al}^{102}$ To explain alterations of walking capacity and patterns, different hypotheses have been put forward. In the Baltimore Longitudinal Study of Aging, a significant correlation between walking speed and maximal voluntary contraction of knee extensor was shown. ${ }^{100}$ The authors' interpretation was that a decrease of knee extensor muscle strength could explain the decline of walking speed with aging. Callisaya et $\mathrm{al}^{103}$ found an association among white matter atrophy and walking speed, step length and cadence. The authors suggested that these results strengthened the evidence of a causal relationship between brain aging and walking decline. In a recent systematic review and metaanalysis, Peel et $\mathrm{al}^{104}$ supported these results by reporting an association between gait speed performance and global cognitive function in community-dwelling older people throughout 16 longitudinal (15,662 participants) and 20 cross-sectional (13,848 participants) studies. This meta-analysis showed reduction of gait speed of $0.11 \mathrm{~m} / \mathrm{s}$ in persons with cognitive impairment, $0.20 \mathrm{~m} / \mathrm{s}$ in those with mild dementia, and of $0.41 \mathrm{~m} / \mathrm{s}$ in those with moderate dementia, compared to cognitively intact older adults. In addition to cognitive functions, walking speed may be related to older people's mobility.

While $85 \%$ of people at the age of 60 years have a normal gait, this proportion drops to $18 \%$ in people aged 85 years. In a predictive model study, Guralnik et al ${ }^{179}$ reported that walking speed is a good predictor of daily living activity disability and mobility impairment. Furthermore, age-related walking speed decline has been associated with increased risk of falls, ${ }^{105}$ quality of life, ${ }^{106}$ health status, ${ }^{107}$ physical function, and mobility, ${ }^{108,109}$ cognitive decline and dementia, ${ }^{110-112}$ and early mortality. ${ }^{113}$ More specifically, Studenski et $\mathrm{al}^{113}$ using individual data from 34,485 community-dwelling older adults (from nine cohort studies) with a follow-up longer than five years, evaluated the relationship between gait speed and survival. The authors reported that survival increases across the full range of gait speeds, with a gait speed of around $0.8 \mathrm{~m} / \mathrm{s}$ at the median life expectancy at most ages for both sexes. 
They reported that gait speed, adjusted by age and sex, provided as accurate as predictions based on age, sex, use of mobility aids, and self-reported function or as predictions based on age, sex, chronic conditions, smoking history, blood pressure, body mass index, and hospitalization. All in all, the authors suggested that gait speed could be used in a simple way as an indicator of the health of older persons, and might help to identify populations that could benefit from preventive intervention. For all these reasons, walking speed has been identified as the sixth vital sign in geriatric assessment, ${ }^{114}$ and could be the main indicator of mobility loss in the older population. In addition to motor function impairment, aging has an impact at the molecular and cellular level.

\section{Molecular and Cellular Factors}

Aging is accompanied by changes in molecular, cellular and organ level and modulated by genetic, behavioral and environmental factors. One of the most important factors in this area is the immune dysregulation producing high blood levels of pro-inflammatory immunogenetic stimulation. ${ }^{115}$ High levels of circulating pro-inflammatory markers, eg Il-1, IL-6 as well as $\mathrm{C}$-reactive protein, transforming growth factor $\beta$ and others are responsible for immune dysregulation and increased inflammation in older age. This pro-inflammatory status is often known as "inflammaging". ${ }^{115}$ Epidemiological studies have demonstrated the negative impact of inflammaging on cardiovascular disease, neurological disorder such as depression or dementia, and furthermore on global health indicators such as frailty, sarcopenia, and mobility limitation. ${ }^{115}$

There is increasing evidence that low physical activity levels increases the accumulation of visceral fat, adipose infiltration by pro-inflammatory immune cells and persistent low-grade inflammation. ${ }^{116}$ In his review article Philipps ${ }^{117}$ provided evidence that long-term physical activity modulates age-related cellular and molecular changes. Physical activity has a positive impact on the inflammatory processes and increases the resilience stress response. ${ }^{117}$

Given that aging induces alterations in strength and power, muscle mass, balance and postural control, walking and mobility, physical activity or an exercise program provide opportunities to reduce and/or to stave off some of the negative effects of aging.

\section{Opportunities}

Evidence suggests that regular physical activity provides substantial health benefits and reduces risk of chronic diseases. In a systematic review, Paterson and Warburton $^{118}$ demonstrated that inactive older persons ran an increased risk of functional limitations. Interestingly, the risk of physical limitations decreased on average about $20 \%$ if the person was only "somewhat active" (level 1 of physical activity). Moderate physical activity reduced even further the risk of functional limitations. It is commonly understood that any type of physical activity, even at low intensity, is one of the most effective strategies designed to counteract the onset of chronic diseases, eg Type II diabetes and cardiovascular disease, ${ }^{119}$ and to support healthy aging. In addition, physical activity decreases mobility limitations, and supports independent status as well as quality of life. ${ }^{120}$ Taylor $^{119}$ stated that physical activity should be regarded as an actual "medicine" due to its large array of health benefits. Hence, several recommendations for older persons to be physically active have been published. ${ }^{121-123}$ These recommendations propose similar advice: an older person should be physically active for about 30 min per day adding up to 150 min per week of moderate physical activity. One has to keep in mind that the term "physical activity" incorporates all movements that increase energy expenditure. Another important point in all of the recommendations addresses the intensity level by proposing moderate or even vigorous levels of physical activity, and the inclusion of strength and balance exercises. ${ }^{121,122}$ With regard to intensity, brisk walking may be considered as moderate and running or jogging as vigorous physical activity. ${ }^{122}$ Nevertheless, most older adults rarely reach moderate-tovigorous intensity on a daily basis and walking at light intensity constitutes the major part of physical activity in which they engage. ${ }^{124}$ Knowing that additional health effects arise from engaging in a higher level of physical activity, especially in structured exercise programs, ${ }^{119,121}$ greater efforts should be made to increase the participation of older adults.

With regard to function, a recent review by Steffl et $\mathrm{al}^{54}$ demonstrated that physical activity also has positive effects on physical function, eg modifying the sarcopenic process. This is in line with the findings by Marzetti et al ${ }^{125}$ With regard to cognitive function, evidence is evolving that physical activity and exercise also have positive effects on cognitive capacities such as memory, attention, or executive function. Although the effects of physical activity on cognitive function vary with regard to physical activity modality (aerobic, strength, or other type), intensity (light, moderate, or vigorous), and various cognitive domains, 
evidence exists that older persons benefit from physical activity or exercise training with regard to cognitive functions and in some cases maintain this benefit over the longterm. $^{126-130}$

With regard to the important issue of fall events in older persons, recent reviews have underlined the importance of targeted, planned, and structured exercise intervention including progressive strength training and challenging balance exercise. ${ }^{131,132}$ It is important to realize that in fall prevention the subcategory of exercise, not the broad-based term of physical activity, has demonstrated positive effects.

Over recent years another construct has been recognized as a key factor: sedentary behavior, which has been found to be an important risk factor for adverse events in older adults. In an EU project, the determinants of sedentary behavior were defined over the life span, and especially in older persons. ${ }^{133}$ Sedentary behavior, or the formal construct of inactivity, has not only demonstrated negative health impact on an individual level, but has also generated deleterious economic and social consequences. Inactivity was responsible for about 5.3 to 5.7 million deaths globally from noncommunicable diseases, which could be prevented if people who were inactive were instead sufficiently active. ${ }^{134}$ These findings are independent of physical activity levels. ${ }^{135}$ Not surprisingly, in most recommendations reduction of sedentary behavior has been included, with the goal of reducing sitting time.122 Several studies have demonstrated the negative health impact of sedentary behavior. ${ }^{133,136}$ Nevertheless, recent research has demonstrated that although replacing sedentary behavior with moderate-to-vigorous physical activity is associated with reduction of sarcopenia rates and with better performance across its determinants in a doseresponse fashion, light physical activity also seemed protective. $^{137}$

In conclusion, these results suggest that even light physical activity, in which most older adults can partake, could contribute to healthy aging, by counteracting one of the most important contributors to functional loss, sarcopenia. $^{138}$ It is evident that physical activity has demonstrated beneficial health effects in older persons, whereas the other side of the coin - sedentary behaviorhas only lately been recognized as equally important. Further research has demonstrated the positive effects of even a small increase in physical activity levels on health outcomes. ${ }^{139}$ While regular physical activity offers clear opportunities to improve health, many challenges are encountered by the older population.

\section{Challenges}

Older persons constitute the most inactive cohort in population-based studies. ${ }^{140,141}$ In Australia, among persons aged 75 years and older, about $75 \%$ are reported not to meet recommended physical activity levels. ${ }^{140}$ Older persons' motivation to engage in physical activity is influenced by behavioral (eg perceptions, self-efficacy) and environmental factors (eg access, availability). Furthermore, different domains add to the complexity of engaging older persons in physical activity: type and intensity of physical activity, group or individual physical activity, organizational issues (morning or afternoon). ${ }^{120,140}$ The need to communicate and translate research findings on the positive effects of physical activity has been recognized lately by investigating the perception of older persons. Communication models such as the elaboration likelihood model (ELM) by Petty and Cacioppo $^{142}$ or behavior-related psychological models such as the health belief model (HBM) or integrated behavior change model (ICBM) have been used. Most models of increased physical activity share as a central point selfefficacy, norms and values, as well as attitudes. ${ }^{143}$ Being "too old" or "at my age, physical activity does not help" are attitudes that pose a barrier to adhering to physical activity recommendations. ${ }^{144,145}$ Low self-efficacy likewise poses a barrier for uptake or maintenance of physical activity or exercise programs. ${ }^{146}$ Taking into account the specificities of the two domains, it is of utmost importance to phrase invitations in a positive manner and to address older persons' perceptions of physical activity. In other words, older persons or future participants in research projects on exercise intervention should be persuaded that they are able to take part or carry out the proposed physical activity. ${ }^{147}$

Several factors that prevent older persons from being physically active have been reported. In a systematic review, Baert et al ${ }^{148}$ provided a theoretical framework for investigating barriers to physical activity in older adults. The social-ecological model used in this systematic review provides different levels to be addressed when investigating these barriers. ${ }^{148}$ The model differentiates intrapersonal, interpersonal, community, and policy-based barriers. A similar differentiation method was used by Bauman et $\mathrm{al}^{149}$ who also identified interpersonal, intrapersonal and extrapersonal factors such as environment and policy. On an intrapersonal level, for example, several factors have been identified as barriers. Baert et al ${ }^{148}$ 
identified health status as a barrier for physical activity, which is in line with the findings of Newson and Kemps ${ }^{150}$ and Lubs et al ${ }^{151}$ However, health status can act as an enabler and motivation to become physically active and thereby improve health outcomes. ${ }^{152,153}$

Further expertise to an increased level of physical activity or exercise programs may be found in the fall prevention research field. ${ }^{154-157}$ Elskamp et al ${ }^{154}$ detected, on an individual level, the following reported reasons for nonactivity: lack of time, impaired mobility or "being too healthy". Furthermore, one study showed that fall risk perception was related to fear of vulnerability, maintenance of autonomy, and interpretation of risk. ${ }^{158}$

In conclusion, increasing physical activity or uptake of exercise intervention in older persons is a challenging and complex task. Several aspects of theoretical psychological models need to be taken into account, and positive wording as well as the highlighting of positive outcomes are of utmost importance in strengthening older persons' belief that they can perform or take part in the proposed activity to follow the recommendations.

\section{Recommendations and Procedures}

Due to current demographic trends, health promotion and physical independence are crucial. The most recent recommendations advise aging people, frail or not, to perform a minimum of 30 min of moderate intensity physical activity such as fast pace walking, at least five days per week (Figure 1). ${ }^{159}$ Further, in a meta-analysis of more than one million men and women, Ekelund et $\mathrm{al}^{160}$ reported that a high level of physical activity, equivalent to 60-75 min of moderate intensity per day, seemed to offset the increased mortality risk associated with prolonged sitting time. More specifically, the study found that the active older persons (about 60-75 min/day) who sit for more than eight hours daily have a significantly lower risk of mortality than people who sit for less than four hours per day with less physical activity (about five min/day). Based on these findings, physical activity can cancel out the deleterious effect of inactivity and be justified in older persons. To date, the largest and longest study on physical activity in the older population is the Lifestyle Interventions and Independence for Elders (LIFE) recently conducted in the US. ${ }^{12}$ This multicenter randomized controlled trial (RCT) assessed the efficacy of a structured exercise program (designated by the authors as a physical activity program) compared to an educational group in preventing disability in 1635 sedentary and functionally limited persons older than 70 years, over a follow-up period of 2.6 years. In the LIFE study, physical intervention was based on a combination of walking (with a goal of $150 \mathrm{~min} /$ week), strength, flexibility and balance exercises at the center twice per week and at home once per week (weeks 1-4), twice per week (4-8 weeks) and up to four times per week (week 8-52). The exercise sessions were individualized, setting an overall target of $30 \mathrm{~min}$ at moderate intensity, $10 \mathrm{~min}$ of strength training of lower limbs, $10 \mathrm{~min}$ of balance training, and flexibility exercises. This study demonstrated that compared with a health education program, a structured moderate-intensity exercise program reduced major mobility disability, persistent mobility disability and a combined outcome of major mobility disability or death over 2.6 years of follow-up.

Although no final results are available of the SPRINTT study yet, initial experiences in the challenges of recruitment in such a population have been reported ${ }^{161}$ after the study protocol had been published. ${ }^{162}$ The SPRINTT study, a phase III, single-blind, multicenter RCT was designed to compare the efficacy of a multicomponent intervention (MCI) program (exercise intervention, nutritional counseling/dietary intervention, and information and communication technology intervention) versus a Healthy Aging Lifestyle Education (HALE) program in prevention of mobility impairment in initially nondisabled older persons with physical frailty and sarcopenia. ${ }^{162}$ Emphasizing a combination of physical activity/exercise and nutritional intervention, the SPRINTT RCT differs from the LIFE study. ${ }^{161}$ The MCI program was based on the exercise protocol of the LIFE study ${ }^{12}$ and consists of aerobic, strength, flexibility, and balance training. ${ }^{12,163}$ The physical activity/exercise program was designed to be performed both at the center (twice a week with an instructor) and at home (3-4 times/week). ${ }^{125}$ As the primary goal is to enhance mobility, strength training intervention is mainly focused on lower extremity exercises, while upper body exercises are carried out at the end of the training session.

Nutrition is a major determinant of muscle health, physical function and overall well-being, especially in older persons. ${ }^{164-166}$ It follows that nutrition may play a role as a part of multicomponent interventions aimed at preserving muscle mass, counteracting physical performance decline and promoting robustness. ${ }^{164,167,168}$ In this context, it is widely acknowledged that a combination of nutrition and exercise programs is one valuable approach to management of sarcopenia and the physical 


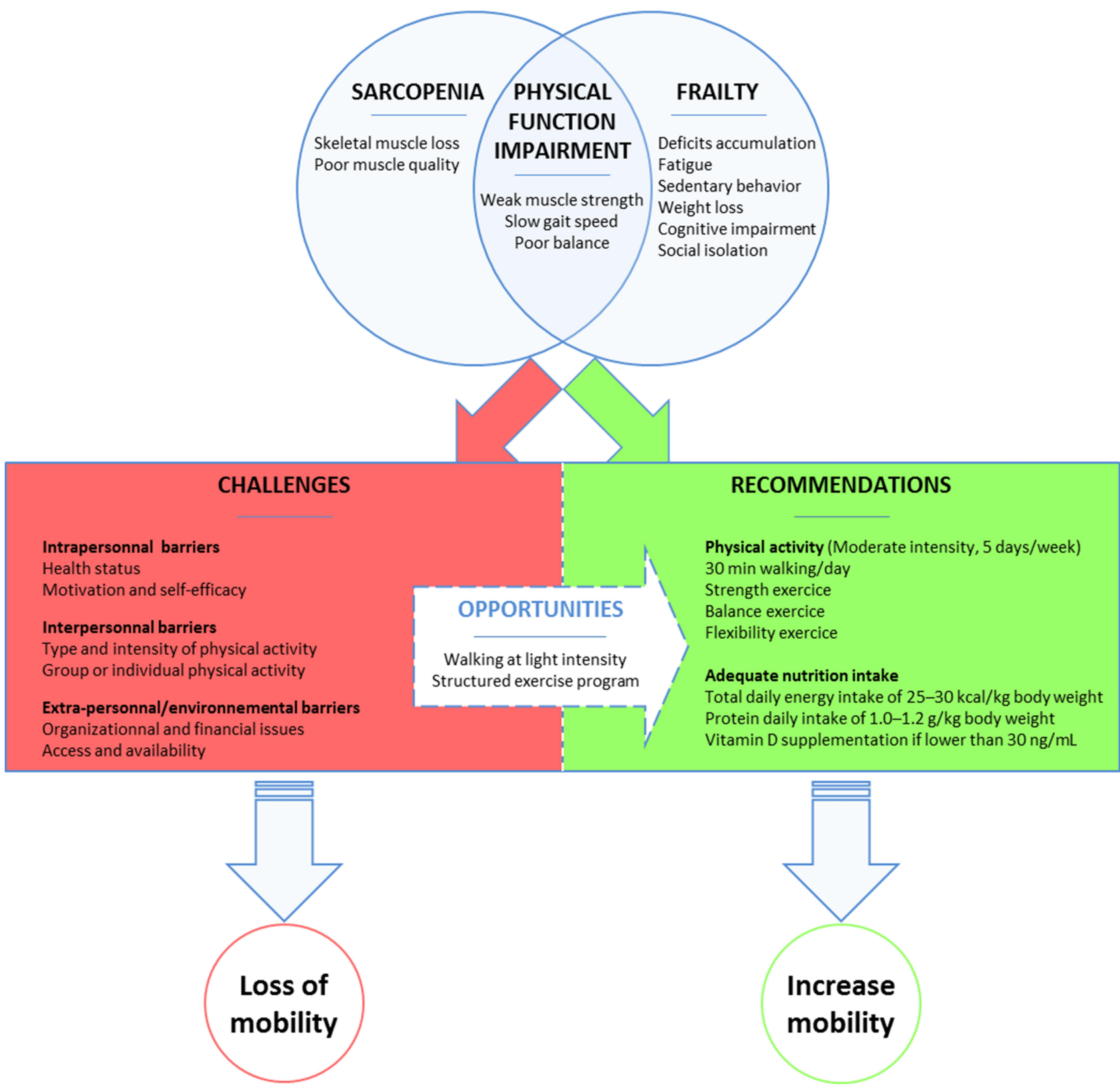

Figure I A Schematic representation summarizes the opportunities, the challenges, the recommendation of physical activity intervention to preserve mobility in older adults with physical frailty and sarcopenia.

components of frailty. ${ }^{164}$ Nutritional patterns conveying adequate daily energy, protein, as well as micronutrients (eg vitamins and plant-derived antioxidants), dietary fiber and healthy oils (in particular extra-virgin olive oil) have shown positive effects on muscle mass, physical function preservation and overall metabolic health. ${ }^{169-172}$ Several strategies may be implemented to design a nutritional plan for older adults involved in physical activity interventions aimed at maximizing the benefits of training and overcoming the traditional barriers that hamper its deployment in real life (ie lack of motivation, low adherence). ${ }^{173,174}$

In the SPRINTT RCT, a multifactorial approach was developed combining a physiologic/metabolic rationale with the educational/behavioral aspects of nutrition. The nutritional intervention of SPRINTT was designed to provide adequate quality and quantity of macro- and micronutrients tailored to the individual's age, gender, health status, physical performance levels, comorbidities and therapies. ${ }^{162}$ Individual preferences as well as a constant and timely 
dialogue between participants and nutritional "trainers" was implemented throughout the trial to increase adherence, motivation and nutritional awareness in older persons. ${ }^{162}$ Two predefined nutritional targets were set according to expert recommendations: (1) a daily total energy intake of 25-30 kcal/kg body weight (corrected by ideal weight when appropriate); and (2) an average protein daily intake of at least $1.0-1.2 \mathrm{~g} / \mathrm{kg}$ body weight. ${ }^{175-177}$ Vitamin D levels were also regularly monitored and supplementation was prescribed if serum concentrations of 25-hydroxyvitamin D (25-OH-D) were below $30 \mathrm{ng} / \mathrm{mL}(75 \mathrm{nmol} / \mathrm{L}) .{ }^{178}$

\section{Conclusion}

Aging induces biological and functional decline at several levels: loss of muscle strength, loss of muscle mass, decline in balance, and subsequent loss of mobility. Sarcopenia and more widely frailty are critical points to address in preventive physical activity/exercise programs to avoid loss of mobility and physical performance. Physical activity and nutritional support to improve physical function and to prevent sarcopenia, frailty and disability are widely recommended in the literature. While the efficacy of long-term physical activity/exercise programs is to date available only in the LIFE study conducted in the US, ${ }^{12}$ the SPRINTT study will provide new evidence of physical activity program feasibility and efficacy to prevent mobility impairment among sarcopenic and physically frail older adults.

\section{Acknowledgments}

The present work was funded by a grant from the Innovative Medicines Initiative-Joint Undertaking (IMIJU 115621). The work was also partially supported by the nonprofit research foundation "Centro Studi Achille e Linda Lorenzon" and by intramural research grants from the Università Cattolica del Sacro Cuore (D3.2 2013 and D3.2 2015).

The authors thank all the participants and the staff involved in the trial for their enthusiastic participation and dedication. The authors would like to thank Jeffrey Arsham for his revision of the English-language manuscript.

\section{Disclosure}

All of the authors of the present work are partners of the SPRINTT consortium, which is partially funded by the European Federation of Pharmaceutical Industries and
Associations (EFPIA). The authors report no potential conflicts of interest in this work.

\section{References}

1. Webber SC, Porter MM, Menec VH. Mobility in older adults: a comprehensive framework. Gerontologist. 2010;50(4):443-450. doi:10.1093/geront/gnq013

2. Bülow J, Ulijaszek SJ, Holm L. Rejuvenation of the term sarcopenia J Appl Physiol. 2019;126(1):255-256. doi:10.1152/japplphysiol. 00400.2018

3. Marzetti E, Calvani R, Tosato M, et al. Sarcopenia: an overview. Aging Clin Exp Res. 2017;29(1):11-17. doi:10.1007/s40520-0160704-5

4. Rosenberg IH. Sarcopenia: origins and clinical relevance. J Nutr 1997;127(5):990S-991S. doi:10.1093/jn/127.5.990S

5. Cruz-Jentoft AJ, Bahat G, Bauer J, et al. Sarcopenia: revised European consensus on definition and diagnosis. Age Ageing. 2019;48(4):601. doi:10.1093/ageing/afz046

6. Anker SD, Morley JE, von Haehling S. Welcome to the ICD-10 code for sarcopenia. J Cachexia Sarcopenia Muscle. 2016;7 (5):512-514. doi:10.1002/jcsm. 12147

7. Fried LP, Tangen CM, Walston J, et al. Frailty in older adults: evidence for a phenotype. J Gerontol a Biol Sci Med Sci. 2001;56 (3):M146-156. doi:10.1093/gerona/56.3.m146

8. Morley JE, Vellas B, van Kan GA, et al. Frailty consensus: a call to action. J Am Med Dir Assoc. 2013;14(6):392-397. doi:10.1016/j. jamda.2013.03.022

9. Hollman JH, McDade EM, Petersen RC. Normative spatiotemporal gait parameters in older adults. Gait Posture. 2011;34(1):111-118. doi:10.1016/j.gaitpost.2011.03.024

10. Caspersen CJ, Powell KE, Christenson GM. Physical activity, exercise, and physical fitness: definitions and distinctions for health-related research. Public Health Rep. 1985;100(2):126-131.

11. Mijnarends DM, Luiking YC, Halfens RJG, et al. Muscle, health and costs: a glance at their relationship. $J$ Nutr Health Aging. 2018;22(7):766-773. doi:10.1007/s12603-018-1058-9

12. Pahor M, Guralnik JM, Ambrosius WT, et al. Effect of structured physical activity on prevention of major mobility disability in older adults: the LIFE study randomized clinical trial. JAMA. 2014;311 (23):2387-2396. doi:10.1001/jama.2014.5616

13. Macaluso A, De Vito G. Muscle strength, power and adaptations to resistance training in older people. Eur J Appl Physiol. 2004;91 (4):450-472. doi:10.1007/s00421-003-0991-3

14. Mitchell WK, Williams J, Atherton P, Larvin M, Lund J, Narici M. Sarcopenia, dynapenia, and the impact of advancing age on human skeletal muscle size and strength; a quantitative review. Front Physiol. 2012;3:260. doi:10.3389/fphys.2012.00260

15. Skelton DA, Greig CA, Davies JM, Young A. Strength, power and related functional ability of healthy people aged $65-89$ years. Age Ageing. 1994;23(5):371-377. doi:10.1093/ageing/23.5.371

16. Kallman DA, Plato CC, Tobin JD. The role of muscle loss in the agerelated decline of grip strength: cross-sectional and longitudinal perspectives. J Gerontol. 1990;45(3):M82-88. doi:10.1093/geronj/45.3.m82

17. Metter EJ, Conwit R, Tobin J, Fozard JL. Age-associated loss of power and strength in the upper extremities in women and men. $J$ Gerontol a Biol Sci Med Sci. 1997;52(5):B267-276. doi:10.1093/ gerona/52a.5.b267

18. Vandervoort AA, McComas AJ. Contractile changes in opposing muscles of the human ankle joint with aging. J Appl Physiol. 1986;61(1):361-367. doi:10.1152/jappl.1986.61.1.361

19. Frontera WR, Hughes VA, Fielding RA, Fiatarone MA, Evans WJ, Roubenoff R. Aging of skeletal muscle: a 12-yr longitudinal study. J Appl Physiol. 2000;88(4):1321-1326. doi:10.1152/jappl.2000.88. 4.1321 
20. Winegard KJ, Hicks AL, Sale DG, Vandervoort AA. A 12-year follow-up study of ankle muscle function in older adults. $J$ Gerontol a Biol Sci Med Sci. 1996;51(3):B202-207. doi:10.1093/ gerona/51a.3.b202

21. Simoneau EM, Billot M, Martin A, Van Hoecke J. Antagonist mechanical contribution to resultant maximal torque at the ankle joint in young and older men. J Electromyogr Kinesiol. 2009;19(2): e123-131. doi:10.1016/j.jelekin.2007.11.006

22. Clark BC, Manini TM. Sarcopenia != Dynapenia. J Gerontol a Biol Sci Med Sci. 2008;63(8):829-834. doi:10.1093/gerona/63.8.829

23. Vandervoort AA. Aging of the human neuromuscular system. Muscle Nerve. 2002;25(1):17-25. doi:10.1002/mus.1215

24. Billot M, Duclay J, Simoneau-Buessinger EM, Ballay Y, Martin A. Is co-contraction responsible for the decline in maximal knee joint torque in older males? Age (Dordr). 2014;36(2):899-910. doi:10.1007/s11357-014-9616-5

25. Bilodeau M, Erb MD, Nichols JM, Joiner KL, Weeks JB. Fatigue of elbow flexor muscles in younger and older adults. Muscle Nerve. 2001;24(1):98-106. doi:10.1002/1097-4598(200101)24:1<98:: AID-MUS11>3.0.CO;2-D

26. Jakobi JM, Rice CL. Voluntary muscle activation varies with age and muscle group. $J$ Appl Physiol. 2002;93(2):457-462. doi:10.11 52/japplphysiol.00012.2002

27. Morse CI, Thom JM, Davis MG, Fox KR, Birch KM, Narici MV. Reduced plantarflexor specific torque in the elderly is associated with a lower activation capacity. Eur J Appl Physiol. 2004;92(12):219-226. doi:10.1007/s00421-004-1056-y

28. Stackhouse SK, Stevens JE, Lee SC, Pearce KM, Snyder-Mackler L, Binder-Macleod SA. Maximum voluntary activation in nonfatigued and fatigued muscle of young and elderly individuals. Phys Ther. 2001;81(5):1102-1109. doi:10.1093/ptj/81.5.1102

29. Stevens JE, Binder-Macleod S, Snyder-Mackler L. Characterization of the human quadriceps muscle in active elders. Arch Phys Med Rehabil. 2001;82(7):973-978. doi:10.1053/apmr.2001.23995

30. Stevens JE, Stackhouse SK, Binder-Macleod SA, Snyder-Mackler L. Are voluntary muscle activation deficits in older adults meaningful? Muscle Nerve. 2003;27(1):99-101. doi:10.1002/mus.10279

31. Yue GH, Ranganathan VK, Siemionow V, Liu JZ, Sahgal V. Older adults exhibit a reduced ability to fully activate their biceps brachii muscle. J Gerontol a Biol Sci Med Sci. 1999;54(5):M249-253. doi:10.1093/gerona/54.5.m249

32. Hortobágyi T, Del Olmo MF, Rothwell JC. Age reduces cortical reciprocal inhibition in humans. Exp Brain Res. 2006;171(3):322329. doi:10.1007/s00221-005-0274-9

33. Kido A, Tanaka N, Stein RB. Spinal excitation and inhibition decrease as humans age. Can J Physiol Pharmacol. 2004;82 (4):238-248. doi:10.1139/y04-017

34. Kamen G. Aging, resistance training, and motor unit discharge behavior. Can J Appl Physiol. 2005;30(3):341-351. doi:10.1139/ h05-126

35. Lexell J, Taylor CC, Sjöström M. What is the cause of the ageing atrophy? Total number, size and proportion of different fiber types studied in whole vastus lateralis muscle from 15- to 83-year-old men. J Neurol Sci. 1988;84(2-3):275-294. doi:10.1016/0022-510X (88) $90132-3$

36. Narici MV, Maganaris CN. Adaptability of elderly human muscles and tendons to increased loading. $J$ Anat. 2006;208(4):433-443. doi:10.1111/j.1469-7580.2006.00548.x

37. Delbono O. Regulation of excitation contraction coupling by insulin-like growth factor-1 in aging skeletal muscle. J Nutr Health Aging. 2000;4(3):162-164.

38. Roubenoff R, Hughes VA. Sarcopenia: current concepts. $J$ Gerontol a Biol Sci Med Sci. 2000;55(12):M716-724. doi:10.1093/gerona/ 55.12.m716

39. Welle S. Cellular and molecular basis of age-related sarcopenia. Can J Appl Physiol. 2002;27(1):19-41. doi:10.1139/h02-002
40. Bean JF, Kiely DK, Herman S, et al. The relationship between leg power and physical performance in mobility-limited older people. $J$ Am Geriatr Soc. 2002;50(3):461-467. doi:10.1046/j.1532-5415.20 02.50111.x

41. Hyatt RH, Whitelaw MN, Bhat A, Scott S, Maxwell JD. Association of muscle strength with functional status of elderly people. Age Ageing. 1990;19(5):330-336. doi:10.1093/ageing/19.5. 330

42. Reid KF, Fielding RA. Skeletal muscle power: a critical determinant of physical functioning in older adults. Exerc Sport Sci Rev. 2012;40(1):4-12. doi:10.1097/JES.0b013e31823b5f13

43. Suzuki T, Bean JF, Fielding RA. Muscle power of the ankle flexors predicts functional performance in community-dwelling older women. J Am Geriatr Soc. 2001;49(9):1161-1167. doi:10.1046/ j.1532-5415.2001.49232.x

44. Bean JF, Leveille SG, Kiely DK, Bandinelli S, Guralnik JM, Ferrucci L. A comparison of leg power and leg strength within the InCHIANTI study: which influences mobility more? J Gerontol a Biol Sci Med Sci. 2003;58(8):728-733. doi:10.1093/gerona/58.8.m728

45. Byrne C, Faure C, Keene DJ, Lamb SE. Ageing, muscle power and physical function: a systematic review and implications for pragmatic training interventions. Sports Med. 2016;46(9):1311-1332. doi:10.1007/s40279-016-0489-x

46. Rantanen T, Avela J. Leg extension power and walking speed in very old people living independently. J Gerontol a Biol Sci Med Sci. 1997;52(4):M225-231. doi:10.1093/gerona/52a.4.m225

47. Cruz-Jentoft AJ, Landi F, Topinková E, Michel J-P. Understanding sarcopenia as a geriatric syndrome. Curr Opin Clin Nutr Metab Care. 2010;13(1):1-7. doi:10.1097/MCO.0b013e328333c1c1

48. Lauretani F, Russo CR, Bandinelli S, et al. Age-associated changes in skeletal muscles and their effect on mobility: an operational diagnosis of sarcopenia. J Appl Physiol. 2003;95(5):1851-1860. doi:10.1152/japplphysiol.00246.2003

49. Morley JE, Anker SD, von Haehling S. Prevalence, incidence, and clinical impact of sarcopenia: facts, numbers, and epidemiologyupdate 2014. J Cachexia Sarcopenia Muscle. 2014;5(4):253-259. doi:10.1007/s13539-014-0161-y

50. Kyle UG, Genton L, Hans D, Karsegard L, Slosman DO, Pichard C. Age-related differences in fat-free mass, skeletal muscle, body cell mass and fat mass between 18 and 94 years. Eur J Clin Nutr. 2001;55(8):663-672. doi:10.1038/sj.ejcn.1601198

51. Janssen I, Heymsfield SB, Wang ZM, Ross R. Skeletal muscle mass and distribution in 468 men and women aged $18-88$ yr. $J$ Appl Physiol. 2000;89(1):81-88. doi:10.1152/jappl.2000.89.1.81

52. Gallagher D, Visser M, De Meersman RE, et al. Appendicular skeletal muscle mass: effects of age, gender, and ethnicity. $J$ Appl Physiol. 1997;83(1):229-239. doi:10.1152/jappl.1997.83.1.229

53. Evans WJ. Skeletal muscle loss: cachexia, sarcopenia, and inactivity. Am J Clin Nutr. 2010;91(4):1123S-1127S. doi:10.3945/ajen.20 $10.28608 \mathrm{~A}$

54. Steffl M, Bohannon RW, Sontakova L, Tufano JJ, Shiells K, Holmerova I. Relationship between sarcopenia and physical activity in older people: a systematic review and meta-analysis. Clin Interv Aging. 2017;12:835-845. doi:10.2147/CIA.S132940

55. Cerri AP, Bellelli G, Mazzone A, et al. Sarcopenia and malnutrition in acutely ill hospitalized elderly: prevalence and outcomes. Clin Nutr. 2015;34(4):745-751. doi:10.1016/j.clnu.2014.08.015

56. Du Y, Karvellas CJ, Baracos V, Williams DC, Khadaroo RG; Acute Care and Emergency Surgery (ACES) Group. Sarcopenia is a predictor of outcomes in very elderly patients undergoing emergency surgery. Surgery. 2014;156(3):521-527. doi:10.1016/j.surg. 2014.04.027

57. Landi F, Liperoti R, Fusco D, et al. Sarcopenia and mortality among older nursing home residents. J Am Med Dir Assoc. 2012;13(2):121-126. doi:10.1016/j.jamda.2011.07.004 
58. Landi F, Cruz-Jentoft AJ, Liperoti R, et al. Sarcopenia and mortality risk in frail older persons aged 80 years and older: results from ilSIRENTE study. Age Ageing. 2013;42(2):203-209. doi:10.1093/ ageing/afs 194

59. Vetrano DL, Landi F, Volpato S, et al. Association of sarcopenia with short- and long-term mortality in older adults admitted to acute care wards: results from the CRIME study. J Gerontol a Biol Sci Med Sci. 2014;69(9):1154-1161. doi:10.1093/gerona/glu034

60. Tarantino U, Baldi J, Celi M, et al. Osteoporosis and sarcopenia: the connections. Aging Clin Exp Res. 2013;25(Suppl 1):S93-95. doi:10.1007/s40520-013-0097-7

61. Drey M, Sieber CC, Bertsch T, Bauer JM, Schmidmaier R. FiAT intervention group. Osteosarcopenia is more than sarcopenia and osteopenia alone. Aging Clin Exp Res. 2016;28(5):895-899. doi:10.1007/s40520-015-0494-1

62. Landi F, Liperoti R, Russo A, et al. Sarcopenia as a risk factor for falls in elderly individuals: results from the ilSIRENTE study. Clin Nutr. 2012;31(5):652-658. doi:10.1016/j.clnu.2012.02.007

63. Tanimoto Y, Watanabe M, Sun W, et al. Sarcopenia and falls in community-dwelling elderly subjects in Japan: defining sarcopenia according to criteria of the European Working Group on sarcopenia in older people. Arch Gerontol Geriatr. 2014;59(2):295-299. doi:10.1016/j.archger.2014.04.016

64. Wu I-C, Lin -C-C, Hsiung CA, et al. Epidemiology of sarcopenia among community-dwelling older adults in Taiwan: a pooled analysis for a broader adoption of sarcopenia assessments. Geriatr Gerontol Int. 2014;14(Suppl 1):52-60. doi:10.1111/ ggi. 12193

65. Grossman DC, Curry SJ, Owens DK, et al.; US Preventive Services Task Force. Interventions to prevent falls in community-dwelling older adults: US preventive services task force recommendation statement. JAMA. 2018;319(16):1696-1704. doi:10.1001/jama.20 18.3097.

66. Cathers I, Day BL, Fitzpatrick RC. Otolith and canal reflexes in human standing. J Physiol (Lond). 2005;563(1):229-234. doi:10.11 13/jphysiol.2004.079525

67. Kavounoudias A, Roll R, Roll JP. The plantar sole is a "dynamometric map" for human balance control. Neuroreport. 1998;9 (14):3247-3252. doi:10.1097/00001756-199810050-00021

68. Paulus WM, Straube A, Brandt T. Visual stabilization of posture. Physiological stimulus characteristics and clinical aspects. Brain. 1984;107(4):1143-1163. doi:10.1093/brain/107.4.1143

69. van Deursen RW, Simoneau GG. Foot and ankle sensory neuropathy, proprioception, and postural stability. J Orthop Sports Phys Ther. 1999;29(12):718-726. doi:10.2519/jospt.1999.29.12.718

70. Billot M, Handrigan GA, Simoneau M, Corbeil P, Teasdale N. Short term alteration of balance control after a reduction of plantar mechanoreceptor sensation through cooling. Neurosci Lett. 2013;535:40-44. doi:10.1016/j.neulet.2012.11.022

71. Billot M, Handrigan GA, Simoneau M, Teasdale N. Reduced plantar sole sensitivity induces balance control modifications to compensate ankle tendon vibration and vision deprivation. $J$ Electromyogr Kinesiol. 2015;25(1):155-160. doi:10.1016/j. jelekin.2014.06.003

72. Hay L, Bard C, Fleury M, Teasdale N. Availability of visual and proprioceptive afferent messages and postural control in elderly adults. Exp Brain Res. 1996;108(1):129-139. doi:10.1007/ BF00242910

73. Manchester D, Woollacott M, Zederbauer-Hylton N, Marin O. Visual, vestibular and somatosensory contributions to balance control in the older adult. $J$ Gerontol. 1989;44(4):M118-127. doi:10.1093/geronj/44.4.M118

74. Woollacott MH. Systems contributing to balance disorders in older adults. J Gerontol a Biol Sci Med Sci. 2000;55(8):M424-428. doi:10.1093/gerona/55.8.m424
75. Aartolahti E, Häkkinen A, Lönnroos E, Kautiainen H, Sulkava R, Hartikainen S. Relationship between functional vision and balance and mobility performance in community-dwelling older adults. Aging Clin Exp Res. 2013;25(5):545-552. doi:10.1007/s40520013-0120-z

76. Saftari LN, Kwon O-S. Ageing vision and falls: a review. J Physiol Anthropol. 2018;37(1):11. doi:10.1186/s40101-018-0170-1

77. Allum JHJ, Carpenter MG, Honegger F, Adkin AL, Bloem BR. Age-dependent variations in the directional sensitivity of balance corrections and compensatory arm movements in man. J Physiol (Lond). 2002;542(2):643-663. doi:10.1113/jphysiol.2001.015644

78. Billot M, Simoneau EM, Van Hoecke J, Martin A. Age-related relative increases in electromyography activity and torque according to the maximal capacity during upright standing. Eur J Appl Physiol. 2010;109(4):669-680. doi:10.1007/s00421-010-1397-7

79. Nagai K, Yamada M, Uemura K, Yamada Y, Ichihashi N, Tsuboyama T. Differences in muscle coactivation during postural control between healthy older and young adults. Arch Gerontol Geriatr. 2011;53(3):338-343. doi:10.1016/j.archger.2011.01.003

80. Cattagni T, Scaglioni G, Laroche D, Van Hoecke J, Gremeaux V, Martin A. Ankle muscle strength discriminates fallers from nonfallers. Front Aging Neurosci. 2014;6:336. doi:10.3389/fnagi.20 14.00336

81. Baudry S, Penzer F, Duchateau J. Vision and proprioception do not influence the excitability of the corticomotoneuronal pathway during upright standing in young and elderly adults. Neuroscience. 2014;268:247-254. doi:10.1016/j.neuroscience.2014.03.026

82. Martínez-Ramírez A, Lecumberri P, Gómez M, Rodriguez-Mañas L, García FJ, Izquierdo M. Frailty assessment based on wavelet analysis during quiet standing balance test. J Biomech. 2011;44 (12):2213-2220. doi:10.1016/j.jbiomech.2011.06.007

83. Teasdale N, Bard C, LaRue J, Fleury M. On the cognitive penetrability of posture control. Exp Aging Res. 1993;19(1):1-13. doi:10.1080/03610739308253919

84. Kubicki A, Bonnetblanc F, Petrement G, Ballay Y, Mourey F. Delayed postural control during self-generated perturbations in the frail older adults. Clin Interv Aging. 2012;7:65-75. doi:10.2147/CIA.S28352

85. Yeung SSY, Reijnierse EM, Pham VK, et al. Sarcopenia and its association with falls and fractures in older adults: a systematic review and meta-analysis. J Cachexia Sarcopenia Muscle. 2019;10 (3):485-500. doi:10.1002/jcsm.12411

86. Zhang X, Huang $\mathrm{P}$, Dou Q, et al. Falls among older adults with sarcopenia dwelling in nursing home or community: a meta-analysis. Clin Nutr. 2019. doi:10.1016/j.clnu.2019.01.002

87. Kim JH, Lim S, Choi SH, et al. Sarcopenia: an independent predictor of mortality in community-dwelling older Korean men. $J$ Gerontol a Biol Sci Med Sci. 2014;69(10):1244-1252. doi:10.1093/ gerona/glu050

88. Senior HE, Henwood TR, Beller EM, Mitchell GK, Keogh JWL. Prevalence and risk factors of sarcopenia among adults living in nursing homes. Maturitas. 2015;82(4):418-423. doi:10.1016/j. maturitas.2015.08.006

89. Lord SR, March LM, Cameron ID, et al. Differing risk factors for falls in nursing home and intermediate-care residents who can and cannot stand unaided. J Am Geriatr Soc. 2003;51(11):1645-1650. doi:10.1046/j.1532-5415.2003.51518.x

90. Goodpaster BH, Park SW, Harris TB, et al. The loss of skeletal muscle strength, mass, and quality in older adults: the health, aging and body composition study. J Gerontol a Biol Sci Med Sci. 2006;61(10):1059-1064. doi:10.1093/gerona/61.10.1059

91. Feldman HA, Longcope C, Derby CA, et al. Age trends in the level of serum testosterone and other hormones in middle-aged men: longitudinal results from the Massachusetts male aging study. J Clin Endocrinol Metab. 2002;87(2):589-598. doi:10.1210/jcem.87.2.8201 
92. Kojima G. Frailty as a predictor of future falls among communitydwelling older people: a systematic review and meta-analysis. $J \mathrm{Am}$ Med Dir Assoc. 2015;16(12):1027-1033. doi:10.1016/j.jamda.2015. 06.018

93. Clegg A, Young J, Iliffe S, Rikkert MO, Rockwood K. Frailty in elderly people. Lancet. 2013;381(9868):752-762. doi:10.1016/ S0140-6736(12)62167-9

94. Laufer Y. Effect of age on characteristics of forward and backward gait at preferred and accelerated walking speed. $J$ Gerontol a Biol Sci Med Sci. 2005;60(5):627-632. doi:10.1093/gerona/60.5.627

95. Samson MM, Crowe A, de Vreede PL, Dessens JA, Duursma SA, Verhaar HJ. Differences in gait parameters at a preferred walking speed in healthy subjects due to age, height and body weight. Aging (Milano). 2001;13(1):16-21. doi:10.1007/BF03351489

96. Beauchet O, Allali G, Annweiler C, et al. Gait variability among healthy adults: low and high stride-to-stride variability are both a reflection of gait stability. Gerontology. 2009;55(6):702-706. doi:10.1159/000235905

97. Dean JC, Alexander NB, Kuo AD. The effect of lateral stabilization on walking in young and old adults. IEEE Trans Biomed Eng. 2007;54(11):1919-1926. doi:10.1109/TBME.2007.901031

98. Schrager MA, Kelly VE, Price R, Ferrucci L, Shumway-Cook A. The effects of age on medio-lateral stability during normal and narrow base walking. Gait Posture. 2008;28(3):466-471. doi:10.10 16/j.gaitpost.2008.02.009

99. Blanke DJ, Hageman PA. Comparison of gait of young men and elderly men. Phys Ther. 1989;69(2):144-148. doi:10.1093/ptj/69.2.144

100. Ko S, Stenholm S, Metter EJ, Ferrucci L. Age-associated gait patterns and the role of lower extremity strength - results from the Baltimore longitudinal study of aging. Arch Gerontol Geriatr. 2012;55(2):474-479. doi:10.1016/j.archger.2012.04.004

101. $\mathrm{Ng} \mathrm{SSM,} \mathrm{Au} \mathrm{KKC,} \mathrm{Chan} \mathrm{ELW,} \mathrm{et} \mathrm{al.} \mathrm{Effect} \mathrm{of} \mathrm{acceleration} \mathrm{and}$ deceleration distance on the walking speed of people with chronic stroke. J Rehabil Med. 2016;48(8):666-670. doi:10.2340/16501 977-2124

102. Wang C-Y, Chen T-R, Lin Y-H, Liu M-H, Chen Y-C. Gait speed measure: the effect of different measuring distances and the inclusion and exclusion of acceleration and deceleration. Percept Mot Skills. 2012;114(2):469-478. doi:10.2466/10.25.26.PMS.114.2.46 9-478

103. Callisaya ML, Beare R, Phan TG, et al. Brain structural change and gait decline: a longitudinal population-based study. J Am Geriatr Soc. 2013;61(7):1074-1079. doi:10.1111/jgs.12331

104. Peel NM, Alapatt LJ, Jones LV, Hubbard RE. The association between gait speed and cognitive status in community-dwelling older people: a systematic review and meta-analysis. J Gerontol a Biol Sci Med Sci. 2019;74(6):943-948. doi:10.1093/gerona/gly140

105. Maki BE. Gait changes in older adults: predictors of falls or indicators of fear. $J$ Am Geriatr Soc. 1997;45(3):313-320. doi:10.1111/j.1532-5415.1997.tb00946.x

106. Ferrucci L, Bandinelli S, Benvenuti E, et al. Subsystems contributing to the decline in ability to walk: bridging the gap between epidemiology and geriatric practice in the InCHIANTI study. J Am Geriatr Soc. 2000;48(12):1618-1625. doi:10.1111/j.1532-5415.2000.tb03873.x

107. Cesari M, Kritchevsky SB, Penninx BWHJ, et al. Prognostic value of usual gait speed in well-functioning older people-results from the health, aging and body composition study. J Am Geriatr Soc. 2005;53(10):1675-1680. doi:10.1111/j.1532-5415.2005.53501.x

108. Newman AB, Simonsick EM, Naydeck BL, et al. Association of long-distance corridor walk performance with mortality, cardiovascular disease, mobility limitation, and disability. JAMA. 2006;295 (17):2018-2026. doi:10.1001/jama.295.17.2018

109. Studenski S, Perera S, Wallace D, et al. Physical performance measures in the clinical setting. J Am Geriatr Soc. 2003;51 (3):314-322. doi:10.1046/j.1532-5415.2003.51104.x
110. Mielke MM, Roberts RO, Savica R, et al. Assessing the temporal relationship between cognition and gait: slow gait predicts cognitive decline in the Mayo Clinic Study of Aging. J Gerontol A Biol Sci Med Sci. 2013;68(8):929-937. doi: 10.1093/gerona/gls256

111. Verghese J, Wang C, Lipton RB, Holtzer R, Xue X. Quantitative gait dysfunction and risk of cognitive decline and dementia. $J$ Neurol Neurosurg Psychiatry. 2007;78(9):929-935. doi:10.1136/ jnnp.2006.106914

112. Watson NL, Rosano C, Boudreau RM, et al. Executive function, memory, and gait speed decline in well-functioning older adults. $J$ Gerontol a Biol Sci Med Sci. 2010;65(10):1093-1100. doi:10.1093/ gerona/glq111

113. Studenski S, Perera S, Patel K, et al. Gait speed and survival in older adults. JAMA. 2011;305(1):50-58. doi:10.1001/jama.2010. 1923

114. Fritz S, Lusardi M. White paper: "walking speed: the sixth vital sign.”. J Geriatr Phys Ther. 2009;32(2):46-49. doi:10.1519/001391 43-200932020-00002

115. Ferrucci L, Fabbri E. Inflammageing: chronic inflammation in ageing, cardiovascular disease, and frailty. Nat Rev Cardiol. 2018;15(9):505-522. doi:10.1038/s41569-018-0064-2

116. Phillips C, Fahimi A. Immune and neuroprotective effects of physical activity on the brain in depression. Front Neurosci. 2018;12:498. doi:10.3389/fnins.2018.00498

117. Phillips C. Physical activity modulates common neuroplasticity substrates in major depressive and bipolar disorder. Neural Plast. 2017;2017:7014146. doi:10.1155/2017/7014146

118. Paterson DH, Warburton DE. Physical activity and functional limitations in older adults: a systematic review related to Canada's physical activity guidelines. Int J Behav Nutr Phys Act. 2010;7:38. doi:10.1186/1479-5868-7-38

119. Taylor D. Physical activity is medicine for older adults. Postgrad Med J. 2014;90(1059):26-32. doi:10.1136/postgradmedj-2012-131 366

120. Amireault S, Baier JM, Spencer JR. Physical activity preferences among older adults: a systematic review. J Aging Phys Act. 2018;112. doi:10.1123/japa.2017-0234

121. Chodzko-Zajko WJ, Proctor DN, Fiatarone Singh MA, et al.; American College of Sports Medicine. American College of Sports Medicine position stand. Exercise and physical activity for older adults. Med Sci Sports Exerc. 2009;41(7):1510-1530. doi:10.1249/MSS.0b013e3181a0c95c.

122. Macera CA, Cavanaugh A, Bellettiere J. State of the Art Review: physical Activity and Older Adults. Am J Lifestyle Med. 2017;11 (1):42-57. doi:10.1177/1559827615571897

123. WHO. Global Recommendations on Physical Activity for Health. Geneva, Switzerland: World Health Organization; 2010.

124. Bijnen FC, Feskens EJ, Caspersen CJ, Mosterd WL, Kromhout D. Age, period, and cohort effects on physical activity among elderly men during 10 years of follow-up: the Zutphen elderly study. $J$ Gerontol a Biol Sci Med Sci. 1998;53(3):M235-241. doi:10.1093/ gerona/53a.3.m235

125. Marzetti E, Calvani R, Tosato M, et al. Physical activity and exercise as countermeasures to physical frailty and sarcopenia. Aging Clin Exp Res. 2017;29(1):35-42. doi:10.1007/s40520-0160705-4

126. Bherer L, Erickson KI, Liu-Ambrose T. A review of the effects of physical activity and exercise on cognitive and brain functions in older adults. J Aging Res. 2013;2013:657508. doi:10.1155/2013/657508

127. Colcombe SJ, Erickson KI, Scalf PE, et al. Aerobic exercise training increases brain volume in aging humans. J Gerontol a Biol Sci Med Sci. 2006;61(11):1166-1170. doi:10.1093/gerona/61.11.1166

128. Engeroff T, Ingmann T, Banzer W. Physical activity throughout the adult life span and domain-specific cognitive function in old age: a systematic review of cross-sectional and longitudinal data. Sports Med. 2018;48(6):1405-1436. doi:10.1007/s40279-018-0920-6 
129. Koščak Tivadar B. Physical activity improves cognition: possible explanations. Biogerontology. 2017;18(4):477-483. doi:10.1007/ s10522-017-9708-6

130. Sáez de Asteasu ML, Martínez-Velilla N, Zambom-Ferraresi F, Casas-Herrero Á, Izquierdo M. Role of physical exercise on cognitive function in healthy older adults: a systematic review of randomized clinical trials. Ageing Res Rev. 2017;37:117-134. doi:10.1016/j.arr.2017.05.007

131. Hopewell S, Adedire O, Copsey BJ, et al. Multifactorial and multiple component interventions for preventing falls in older people living in the community. Cochrane Database Syst Rev. 2018;7: CD012221. doi:10.1002/14651858.CD012221.pub2

132. Sherrington C, Fairhall NJ, Wallbank GK, et al. Exercise for preventing falls in older people living in the community. Cochrane Database Syst Rev. 2019;1:CD012424. doi:10.1002/14651858. CD012424.pub2

133. Chastin SFM, Buck C, Freiberger E, et al. Systematic literature review of determinants of sedentary behaviour in older adults: a DEDIPAC study. Int $J$ Behav Nutr Phys Act. 2015;12:127. doi:10.1186/s12966-015-0292-3

134. Kohl HW, Craig CL, Lambert EV, et al. The pandemic of physical inactivity: global action for public health. Lancet. 2012;380 (9838):294-305. doi:10.1016/S0140-6736(12)60898-8

135. Koster A, Caserotti P, Patel KV, et al. Association of sedentary time with mortality independent of moderate to vigorous physical activity. PLoS One. 2012;7(6):e37696. doi:10.1371/journal.pone.0037696

136. Lee I-M, Shiroma EJ, Lobelo F, et al. Effect of physical inactivity on major non-communicable diseases worldwide: an analysis of burden of disease and life expectancy. Lancet. 2012;380 (9838):219-229. doi:10.1016/S0140-6736(12)61031-9

137. Sánchez-Sánchez JL, Mañas A, García-García FJ, et al. Sedentary behaviour, physical activity, and sarcopenia among older adults in the TSHA: isotemporal substitution model. J Cachexia Sarcopenia Muscle. 2019;10(1):188-198. doi:10.1002/jcsm.12369

138. Suetta C, Haddock B, Alcazar J, et al. The Copenhagen Sarcopenia Study: lean mass, strength, power, and physical function in a Danish cohort aged 20-93 years. J Cachexia Sarcopenia Muscle. 2019;10(6):1316-1329. doi:10.1002/jcsm.12477

139. Wen CP, Wai JPM, Tsai MK, et al. Minimum amount of physical activity for reduced mortality and extended life expectancy: a prospective cohort study. Lancet. 2011;378(9798):1244-1253. doi:10.1016/S0140-6736(11)60749-6

140. Franco MR, Tong A, Howard K, et al. Older people's perspectives on participation in physical activity: a systematic review and thematic synthesis of qualitative literature. Br J Sports Med. 2015;49 (19):1268-1276. doi:10.1136/bjsports-2014-094015

141. Sun F, Norman IJ, While AE. Physical activity in older people: a systematic review. BMC Public Health. 2013;13:449. doi:10.1186/ 1471-2458-13-449

142. Petty RE, Cacioppo JT. The elaboration likelihood model of persuasion. Adv Exp Soc Psychol. 1986;19:123-205.

143. Hagger MS, Chatzisarantis NLD. An integrated behavior change model for physical activity. Exerc Sport Sci Rev. 2014;42(2):62-69. doi:10.1249/JES.0000000000000008

144. Zunft HJ, Friebe D, Seppelt B, et al. Perceived benefits and barriers to physical activity in a nationally representative sample in the European Union. Public Health Nutr. 1999;2(1A):153-160. doi:10.1017/S1368980099000208

145. Chang M, Leveille S, Cohen-Mansfield J, Guralnik JM. The association of physical-performance level with attitude toward exercise in older adults. J Aging Phys Act. 2003;11(2):254-264. doi:10. 1123/japa.11.2.254

146. Lee -L-L, Arthur A, Avis M. Using self-efficacy theory to develop interventions that help older people overcome psychological barriers to physical activity: a discussion paper. Int J Nurs Stud. 2008;45(11):1690-1699. doi:10.1016/j.ijnurstu.2008.02.012
147. Sales M, Levinger P, Polman R. Relationships between self perceptions and physical activity behaviour, fear of falling, and physical function among older adults. Eur Rev Aging Phys Act. 2017;14:17. doi:10.1186/s11556-017-0185-3

148. Baert V, Gorus E, Mets T, Geerts C, Bautmans I. Motivators and barriers for physical activity in the oldest old: a systematic review. Ageing Res Rev. 2011;10(4):464 474. doi:10.1016/j.arr.2011.04.001

149. Bauman AE, Reis RS, Sallis JF, et al. Correlates of physical activity: why are some people physically active and others not? Lancet. 2012;380(9838):258-271. doi:10.1016/S0140-6736(12)60735-1

150. Newson RS, Kemps EB. Factors that promote and prevent exercise engagement in older adults. J Aging Health. 2007;19(3):470-481. doi:10.1177/0898264307300169

151. Lübs L, Peplies J, Drell C, Bammann K. Cross-sectional and longitudinal factors influencing physical activity of 65 to 75 -year-olds: a pan European cohort study based on the survey of health, ageing and retirement in Europe (SHARE). BMC Geriatr. 2018;18(1):94. doi:10.1186/s12877-018-0781-8

152. Kaleta D, Makowiec-Dabrowska T, Dziankowska-Zaborszczyk E, Jegier A. Physical activity and self-perceived health status. Int $J$ Occup Med Environ Health. 2006;19(1):61-69. doi:10.2478/ v10001-006-0005-x

153. Loprinzi PD, Frith E. Association between perceived physical activity and cognitive function in older adults. Psychol Rep. 2019;122(1):108-116. doi:10.1177/0033294117750632

154. Elskamp ABM, Hartholt KA, Patka P, van Beeck EF, van der Cammen TJM. Why older people refuse to participate in falls prevention trials: a qualitative study. Exp Gerontol. 2012;47 (4):342-345. doi:10.1016/j.exger.2012.01.006

155. Gardiner S, Glogowska M, Stoddart C, Pendlebury S, Lasserson D, Jackson D. Older people's experiences of falling and perceived risk of falls in the community: a narrative synthesis of qualitative research. Int J Older People Nurs. 2017;12(4):e12151. doi:10.11 11/opn.12151

156. Hill KD, Day L, Haines TP. What factors influence communitydwelling older people's intent to undertake multifactorial fall prevention programs? Clin Interv Aging. 2014;9:2045-2053. doi:10.2147/CIA.S72679

157. Yardley L, Donovan-Hall M, Francis K, Todd C. Attitudes and beliefs that predict older people's intention to undertake strength and balance training. J Gerontol B Psychol Sci Soc Sci. 2007;62(2): P119-125. doi:10.1093/geronb/62.2.p119

158. McMahon S, Talley KM, Wyman JF. Older people's perspectives on fall risk and fall prevention programs: a literature review. Int $J$ Older People Nurs. 2011;6(4):289-298. doi:10.1111/j.1748-3743. 2011.00299.x

159. Cruz-Jentoft AJ, Landi F, Schneider SM, et al. Prevalence of and interventions for sarcopenia in ageing adults: a systematic review. Report of the International Sarcopenia Initiative (EWGSOP and IWGS). Age Ageing. 2014;43(6):748-759. doi:10.1093/ageing/afu115

160. Ekelund U, Steene-Johannessen J, Brown WJ, et al. Does physical activity attenuate, or even eliminate, the detrimental association of sitting time with mortality? A harmonised meta-analysis of data from more than 1 million men and women. Lancet. 2016;388 (10051):1302-1310. doi:10.1016/S0140-6736(16)30370-1

161. Marzetti E, Cesari M, Calvani R, et al. The "Sarcopenia and physical frailty in older people: multi-component treatment strategies" (SPRINTT) randomized controlled trial: case finding, screening and characteristics of eligible participants. Exp Gerontol. 2018;113:48-57. doi:10.1016/j.exger.2018.09.017

162. Landi F, Cesari M, Calvani R, et al. The "Sarcopenia and physical frailty in older people: multi-component treatment strategies" (SPRINTT) randomized controlled trial: design and methods. Aging Clin Exp Res. 2017;29(1):89-100. doi:10.1007/s40520-0160715-2 
163. Fielding RA, Rejeski WJ, Blair S, et al. The lifestyle interventions and independence for elders study: design and methods. J Gerontol a Biol Sci Med Sci. 2011;66(11):1226-1237. doi:10.1093/gerona/glr123

164. Calvani R, Miccheli A, Landi F, et al. Current nutritional recommendations and novel dietary strategies to manage sarcopenia. $J$ Frailty Aging. 2013;2(1):38-53.

165. Azzolino D, Arosio B, Marzetti E, Calvani R, Cesari M. Nutritional status as a mediator of fatigue and its underlying mechanisms in older people. Nutrients. 2020;12(2):444. doi:10.3390/nu12020444

166. Lorenzo-López L, Maseda A, de Labra C, Regueiro-Folgueira L, Rodríguez-Villamil JL, Millán-Calenti JC. Nutritional determinants of frailty in older adults: a systematic review. BMC Geriatr. 2017;17(1):108. doi:10.1186/s12877-017-0496-2

167. Robinson SM, Reginster JY, Rizzoli R, et al. Does nutrition play a role in the prevention and management of sarcopenia? Clin Nutr. 2018;37(4):1121-1132. doi:10.1016/j.clnu.2017.08.016

168. Cruz-Jentoft AJ, Kiesswetter E, Drey M, Sieber CC. Nutrition, frailty, and sarcopenia. Aging Clin Exp Res. 2017;29(1):43-48. doi:10.1007/s40520-016-0709-0

169. Ntanasi E, Yannakoulia M, Kosmidis M-H, et al. Adherence to Mediterranean Diet and Frailty. J Am Med Dir Assoc. 2018;19 (4):315-322.e2. doi:10.1016/j.jamda.2017.11.005

170. Montiel-Rojas D, Nilsson A, Santoro A, et al. Dietary fibre may mitigate sarcopenia risk: findings from the NU-AGE cohort of older European adults. Nutrients. 2020;12(4):1075. doi:10.3390/ nu12041075

171. Behrouzi P, Grootswagers P, Keizer PLC, et al. Dietary intakes of vegetable protein, folate, and vitamins B- 6 and B-12 are partially correlated with physical functioning of Dutch older adults using copula graphical models. $J$ Nutr. 2020;150(3):634-643. doi:10.10 93/jn/nxz269

172. Ghosh TS, Rampelli S, Jeffery IB, et al. Mediterranean diet intervention alters the gut microbiome in older people reducing frailty and improving health status: the NU-AGE 1-year dietary intervention across five European countries. Gut. 2020;69(7):1218-1228. doi:10.1136/gutjnl-2019-319654

173. Dedeyne L, Dewinter L, Lovik A, Verschueren S, Tournoy J, Gielen E. Nutritional and physical exercise programs for older people: program format preferences and (dis)incentives to participate. Clin Interv Aging. 2018;13:1259-1266. doi:10.2147/CIA. S159819

174. Hsieh T-J, Su S-C, Chen C-W, et al. Individualized home-based exercise and nutrition interventions improve frailty in older adults: a randomized controlled trial. Int J Behav Nutr Phys Act. 2019;16 (1):119. doi:10.1186/s12966-019-0855-9
175. Correia MITD, Hegazi RA, Higashiguchi T, et al. Evidence-based recommendations for addressing malnutrition in health care: an updated strategy from the feedM.E. Global study group. $J \mathrm{Am}$ Med Dir Assoc. 2014;15(8):544-550. doi:10.1016/j.jamda.2014. 05.011

176. Bauer J, Biolo G, Cederholm T, et al. Evidence-based recommendations for optimal dietary protein intake in older people: a position paper from the PROT-AGE study group. $J$ Am Med Dir Assoc. 2013;14(8):542-559. doi:10.1016/j.jamda.2013.05.021

177. Deutz NEP, Bauer JM, Barazzoni R, et al. Protein intake and exercise for optimal muscle function with aging: recommendations from the ESPEN expert group. Clin Nutr. 2014;33(6):929-936. doi:10.1016/j.clnu.2014.04.007

178. American Geriatrics Society Workgroup on Vitamin D Supplementation for Older Adults. Recommendations abstracted from the American Geriatrics Society Consensus Statement on vitamin $\mathrm{D}$ for prevention of falls and their consequences. $\mathrm{J} \mathrm{Am}$ Geriatr Soc. 2014;62(1):147-152. doi:10.1111/jgs.12631.

179. Guralnik JM, Ferrucci L, Pieper CF, et al. Lower extremity function and subsequent disability: consistency across studies, predictive models, and value of gait speed alone compared with the short physical performance battery. J Gerontol a Biol Sci Med Sci. 2000;55(4):M221-231. doi:10.1093/gerona/55.4.m221

180. Tinetti ME, Williams TF, Mayewski R. Fall risk index for elderly patients based on number of chronic disabilities. Am J Med. 1986;80(3):429-434. doi:10.1016/0002-9343(86)90717-5

181. Vellas BJ, Wayne SJ, Romero L, Baumgartner RN, Rubenstein LZ, Garry PJ. One-leg balance is an important predictor of injurious falls in older persons. J Am Geriatr Soc. 1997;45(6):735-738. doi:10.1111/j.1532-5415.1997.tb01479.x

182. Berg K, Wood-Dauphine S, Williams JI, Gayton D. Measuring balance in the elderly: preliminary development of an instrument. Physiother Can. 2009. doi:10.3138/ptc.41.6.304

183. Rolland YM, Cesari M, Miller ME, Penninx BW, Atkinson HH, Pahor M. Reliability of the 400-m usual-pace walk test as an assessment of mobility limitation in older adults. $J$ Am Geriatr Soc. 2004;52(6):972-976. doi:10.1111/j.1532-5415.2004.52267.x

184. Harada ND, Chiu V, Stewart AL. Mobility-related function in older adults: assessment with a 6-minute walk test. Arch Phys Med Rehabil. 1999;80(7):837-841. doi:10.1016/s0003-9993(99)90236-8

185. Podsiadlo D, Richardson S. The timed "Up \& Go": a test of basic functional mobility for frail elderly persons. $J$ Am Geriatr Soc. 1991;39(2):142-148. doi:10.1111/j.1532-5415.1991.tb01616.x
Clinical Interventions in Aging

\section{Publish your work in this journal}

Clinical Interventions in Aging is an international, peer-reviewed journal focusing on evidence-based reports on the value or lack thereof of treatments intended to prevent or delay the onset of maladaptive correlates of aging in human beings. This journal is indexed on PubMed Central, MedLine, CAS, Scopus and the Elsevier
Bibliographic databases. The manuscript management system is completely online and includes a very quick and fair peer-review system, which is all easy to use. Visit http://www.dovepress.com/ testimonials.php to read real quotes from published authors. 